\title{
If Intervention Is Method, What Are We Learning?
}

\author{
A Commentary on Brian Martin's “STS and Researcher Intervention Strategies"
}

\author{
TEUN ZUIDERENT-JERAK \\ Linköping University
}

\begin{abstract}
In STS and Researcher Intervention Strategies, Brian Martin expresses his concern about the lack of strategic guidance STS offers for intervening in controversies in which actors are being marginalized. This is an interesting contrast with some classic critiques of Actor-Network Theory. Leigh Star famously argued that the over-emphasis of ANT on strategic action made it particularly poorly equipped to study heterogeneity-an analytical and political problem at once. I argue that guidance on intervention as research method should actively resist the urge to make intervention "strategic." Considering intervention as a scholarly method for producing novel insights about our topics is diametrically opposed to considering intervention strategically, that is, as means to achieving predefined scholarly or normative goals. Drawing on previous, recent, and ongoing work on intervention as an equally non-strategic and nondetached method for developing new knowledge and new normativities, I explore how such work would speak to Martin's challenge of intervening in controversies and what could be some interesting lessons such an experiment might spark. A strategic take on intervention is important for Martin because it challenges a linear model of STS knowledge production: scholars prioritizing the development of greater understanding of phenomena, hoping that such knowledge can then be beneficial for society later on. Approaching intervention as method, however, challenges problematic linear models of STS knowledge, not by inverting the linearity (from areas of social importance to knowledge production), but by extending non-linear scholarship to our own and others' normativities. This allows STS scholars to take their concerns about the practices they are involved in seriously without violating their equal attachment to reflexivity, unpredictability, and situatedness. Such a prospect may help STS scholars to explore what it means to live the multiple membership of societally and academically concerned communities, which is what considering intervention strategically would make us lose.
\end{abstract}

\section{Keywords}

intervention; methods; sentimentality; artful contamination; normativity

'Teun Zuiderent-Jerak, Department of Thematic Studies - Technology and Social Change Linköping University. Email: teun.zuiderent-jerak@liu.se

Copyright ( 120156 (Teun Zuiderent-Jerak) Licensed under the Creative Commons Attribution Non-commercial No Derivatives (by-nc-nd). Available at estsjournal.org. 


\section{Strategic Methods for Difference?}

How strategic can or should STS be in order to care for difference and act against the marginalization of actors? This is a question Brian Martin raises (Martin 2016), but it also resonates with Susan Leigh Star's classic concern about the attention Actor-Network Theory pays to strategic network-building activities. Drawing attention to how the notion of "translation," central to ANT, privileges network-building by strategic actors over the experience of being marginal, Star indicated that ANT is poorly equipped to attend to heterogeneity in networks. She didn't say that difference could not be studied with ANT, but that, due to its starting point of studying strategic network building actors, heterogeneity became "difficult to see or understand except in terms of deviance or 'other' as long as they are seen in terms of the executive mode of power relations" (1991, p.48). The problem was that when studying power relations in an "executive mode," that is, focusing on the strategic acts by network builders to enroll ever more actors and marginalize others, whatever does not belong to the network becomes its "other," its "deviant," rather than something that persists alongside, though possibly affected by, and/or differently relates to, the network. Star saw this as a major limitation of the strategic features of ANT, both analytically and politically.

This argument came to mind when thinking with Brian Martin's contribution, which I read mainly as a concern about the lack of strategic guidance that STS offers to intervene in situations where actors are being marginalized. How does his call for more strategy guidance on intervening on behalf of marginalized actors in controversies relate to Star's earlier criticism of ANT being overly strategic? Could Martin's calls for strategy, this time on behalf of the marginalized, perhaps provide a solution to the concerns Star raised? To put it differently, would her concerns vanish if only Latour hadn't started with Pasteur, but with the marginalized herbalists whose knowledge some are now, in times of antibiotics resistance, eagerly trying to recover? Can strategy be safely reinstated as something STS should "have more of," as long as it guides intervention to support the marginalized; for causes that are "good enough"? These are important questions that speak equally to our personal troubles and our academic concerns, and in this commentary I share some thoughts on them, but mainly express hope for continued conversations on the pages of this and other journals.

In these few pages, I question the idea that STS faces the problem of a lack of guidance on intervention as a research method. Instead, I argue that for methodological, analytical and normative reasons, all such guidance should advise scholars to actively resist the urge to make intervention "strategic." Considering intervention as a scholarly method for producing novel insights about our topics as well as about our own ways of relating to them is diametrically opposed to considering intervention strategically, that is, as means to achieving predefined scholarly or normative goals. By developing this point, I am not trying to unleash a "controversy on intervention"; I am rather hoping to explore how scholarly work can intervene in controversies in ways that do something different than re-iterate actorpositions, that is, repeat and thereby reproduce the same ordering of the controversy that is initially encountered, and to consider what STS may be learning from such work. I do so because I fear that, in spite of the fact that Martin starts his analysis from the standpoint of those marginalized in a controversy, which in some way is the exact opposite of ANTs "executive mode," he may well risk reproducing the very same analytical and political 
problems: where an "executive" analysis is only able to see those marginalized as "deviant," Martin's "marginal" analysis is only able to see those who dominate the controversy as "in power." Controversies, whether studied from "top" or "bottom," then come to consist of pregiven positions that the STS analysis further ossifies, repeats, reiterates, leaving those involved in the controversy with limited options: they either fight for or acquiesce to their marginalization.

My hope is that intervention can do something different than accept and repeat such given positions. Could intervention perhaps be explored methodologically to "keep open" such polarized understandings of controversies? Would there be something to gain, as Sonja Jerak-Zuiderent proposes, in mobilizing STS intervention methods to resist "both the sticky tendency of normalizing accounts and the fallacy of misplaced concreteness" (2015, p.897)? Could intervention perhaps contribute to resisting such sticky understandings of controversies that could easily be experienced as "living a bad dream, somebody else's imaginary" (Latimer and Skeggs 2011: 408)? The "turd" that Martin needs to take indicates that the reasons for wanting to explore this option can be equally scholarly and personal: receiving the harsh, slanderous responses he gets to his work would surely qualify this as "living a bad dream" to me.

\section{Asking Too Much and Too Little of Intervention as Method}

One of Martin's main concerns is that "STS lacks tools for guiding practical action." This is odd, Martin writes, since "if intervening is one research method, then STS, or at least social science more generally, should offer some guidance, just as it does for undertaking discourse analysis, historiography, or policy advice." I generally hadn't considered "policy advice" to be a research method, but I don't think that this is just a slip of the pen. I actually find it an interesting proposal to consider how advising policy can be a research method, that is, how the process of policy advice can become an approach to studying the topic one is advising on. Martin, however, seems to include policy advice not so much with the aim of empirically unpacking it, but rather because it relates to telling someone what they should do, which for him seems to be an important aspect of methods. Each of his empirical episodes of intervening in the controversy around vaccination is concluded with an observation on receiving too little guidance on "what to do." And some of the guidance Martin expects would be highly specific, for example "whether or how to respond to complaints to one's employer" for which "STS does not provide any guidance." Asking for such detailed instructions on what to do seems to me like asking too much from a method of interventionjust like I would not expect guidance from interviewing methodology on whom exactly to interview or what questions to ask. This expectation, therefore, indeed, seems related to the above-cited concern about misplaced concreteness. It is misplaced not only in the philosophical Whiteheadian sense of mistaking the abstract (an approach) for the concrete (what to do) (Whitehead 2011 [1926]), but particularly since such guidance is not available to

\footnotetext{
= I thank Katie Vann for helping me articulate this point. The risk of reproducing such analytical and political limitations by starting simply from "the other end" of the development of an actor-network can be observed in Galis and Lee (2014), an article that does not engage with Star's earlier criticism on the limitations of an "executive mode" in ANT analysis.

Quoted in Jerak-Zuiderent (2015).

See for an exploration along these lines see, Webster (2007) and the debate it sparked.
} 
any of the other actors involved in the controversy. Asking STS methods to provide a clarity that is not available to anybody else surely must be too much to ask.

By asking for concrete instructions on how to act strategically, Martin also seems to ask too little of intervention as method for STS scholarship. For if we were in the unique position of knowing exactly what to do, how would this then allow for the possibility of learning from intervening? We wouldn't be learning about how to do the things we're doing, as those would already be prescribed by the strategic method guidance (merely letting us prove/disprove/refine the prescriptive intervention method); nor would we be developing novel insights about the controversy studied, as the dynamics at play would already need to be known for the prescription to "work." And this is a problem that Martin, indeed, struggles with: the ruptures his interventions produce are, he writes, "exactly the sort of response I described in my article 'debating vaccination,'” and in this sense intervening seemed to make the experience analytically repetitive. Though the experience of the controversy must be a different one when it gets directed at oneself, that experience would, to me, both methodologically and personally, only be worth it if it also produced some other insights about the controversy.

With this I don't mean to indicate that our personal concerns and the suffering we become aware of are to be cut off from our scholarly interests, but rather that those should somehow relate productively. When Martin indicates that the only point of reference within STS for choosing a research topic is "the vague criterion that areas be 'interesting,"' this does little justice to the long traditions in STS and sociology at large of working on topics that scholars somehow care about, while equally trying to resist calls on them to come up with "solutions" for which they need to accept pre-defined problem-spaces. Drawing upon such traditions that acknowledge the interrelation of scholarly and normative concerns, STS methods would rather need to call "simultaneous attention to the engagement of actors and practices in STS fields of work and to reflexive learning from those actors and practices" (Downey and Zuiderent-Jerak 2016). Intervention thereby becomes equally about the production of new STS knowledge and about the production of new normativity (ZuiderentJerak 2015). As soon as intervention becomes "strategic," the chances for the development of such new knowledge and new normativity are minimized.

Given these methodological, analytical, and normative limitations of a strategic understanding of intervention methods, I would like to take up the challenge Martin poses somewhat more directly, by pointing to some of the inspirations I draw upon to develop intervention as an equally non-strategic and non-detached scholarly method, and that I explore in more detail in Situated Intervention: Sociological Experiments in Health Care.

\section{Guidance for Intervention as Method in Controversy-Studies Take Sides, Avoid Sentimentality}

One of the most interesting lessons on the interrelation of the production of new knowledge and new normativity comes from a predecessor of STS work on how to relate to controversies: Howard Becker's classic paper Whose Side Are We On? (1967), a contribution that is usually cited as arguing in favor of taking sides-as in the case of Martin with free

see Jensen (2008) for an elegant elaboration of this tension. 
speech and therefore with Meryl Dorey and the Australian Vaccination Network (AVN). This is, however, not quite what Becker claims. Although he states that value-neutrality is "imaginary" (ibid., p. 239), and also that sociologists "usually take the side of the underdog" (ibid., p. 244), he crucially also argues that sociologists ought "to make sure that, whatever point of view we take, our research meets the standards of good scientific work, that our unavoidable sympathies do not render our results invalid" (ibid., p. 246). He specifies this general concern by introducing two related principles: first, sociologists should "avoid sentimentality," meaning that scholars should not shun finding out "what is going on, if to know would be to violate some sympathy"; and second, sociologists should study "impartially," meaning that scholarship should be designed so that "a belief to which we are especially sympathetic could be proved untrue."

In the case of vaccination, this could be seen as guidance to focus on an empirical analysis of those debates and practices within the vaccination controversy that problematize the idea that Martin now adopts - that there is only one main, dominant narrative consisting of a "push for universal vaccination for ever more diseases," with vaccination being "seen as a safe and effective way to reduce risk of disease." Even if one is generally sympathetic to such understandings of controversies around vaccination, it would be advisable in terms of scholarship, if one is convinced by Becker's suggestions, to avoid sentimentality about such understandings and design an intervention in such a way that this attachment could be put at risk. Publishing a contribution in the AVN magazine Living Wisdom would then not be my first option, as this risks reifying the split between the sides of the controversy and thereby also an attachment to seeing the "other side" of the controversy as merely advocating "vaccination-push."

In Martin's paper, the unsurprising pushback is a mere repetition of previous responses, confirming rather than putting at risk the attachment to critiquing "the" vaccination movement. Reifying the sides of the controversy may well hide differences between vaccination-related actors from view. Putting one's sympathy for the vaccination critics at risk could be done by thinking about possible vaccination actors who may be equally critical of the harshness of the critique on the AVN. Those could be policy-makers concerned about the reception of vaccination after resistance to HPV campaigns, or doctors with critical ideas about pharma-push for vaccines, etc. Would it be possible to write something together with them and publish it in a medical journal? And what could one learn from such co-authorship? What attachments would one need to renounce upon? And which ones would one gain? How would such an experimental intervention sort the attachments (Jensen 2007) of the STS scholar and of the others involved? In my own work on evidencebased medicine, a domain that is often approached in critical terms, I have possibly learnt most from precisely such an experiment, by needing to critically point to some current problems in EBM while needing to stay far away from repetitive, stereotypical sociological EBM critiques (Zuiderent-Jerak, Forland, and Macbeth 2012).

\section{Artful contamination through finding frictions within}

This brings me to a second, related guidance that I take from feminist science studies scholar Sarah Kember. In her attempt to explore another position for feminism than distanced critique, Kember notes that other disciplines often turn out to be "far from unified and in fact 
highly contested internally[,] the strongest critique ... com[ing] from within the discipline" (2003, p.176). Those critiques from within could be interesting in Martin's case, because they are unlikely to fit the ordering of the problem as a pro-contra vaccination issue, and thereby challenge the conceptual/normative understandings that produce the controversy--and that STS scholarship risks reproducing.

In the case of my own work on EBM, I found during fieldwork and interviews that the concept of a "hierarchy of evidence" with (meta-reviews of) randomized controlled trials (RCTs) at the top, was not merely challenged by sociologists who criticize the naïve epistemological politics of the EBM movement (Goldenberg 2006). It was also heavily contested within this "movement," or rather, this internally diverse field of practice. I noticed that some of the most interesting critiques of naïve epistemology came from leading EBM practitioners and researchers. Moreover, I discovered that the founders of EBM, even in the very papers that critical sociologists cited as introducing the hierarchy of evidence, had explicitly argued against such a naïve understanding. In an attempt to clarify what EBM is and is not, they had stated that EBM "is not restricted to randomised trials and metaanalyses. It involves tracking down the best external evidence with which to answer our clinical questions" (Sackett et al. 1996). But in spite of such more nuanced understandings of evidence, in practice many guideline developers were struggling with feeling the need to somehow fit all forms of knowledge into this accursed hierarchy. Exploring this further with critical EBM practitioners, we concluded that the issue such practitioners face is not so much one of epistemology, but one of knowledge appraisal infrastructures: the dominant guideline development infrastructures all had the hierarchy of evidence built into them. As an experimental intervention, we initiated a Working Group within the Guidelines International Network (GIN), the professional association of guideline developers, on Appraising and Including Different Knowledge (AID Knowledge), which works toward making available a wider set of knowledge appraisal infrastructures.

The reason to mention this here is that such an intervention and the continued learning it requires could only emerge because I noticed that the positions within EBM practitioners were so diverse and often interestingly nuanced--at times more so than the positions I encountered among critical colleagues. Such learning from engaging with the frictions within what would otherwise appear as one of the "sides" of the controversy is what I have called "artful contamination" (2010). With this notion I wish to point to how contaminating STS understandings with the nuanced understanding of actors within a diversified field can prevent scholarship from getting locked into pre-given and analytically limiting problem spaces, and can help prevent STS attachments from turning into sentimentality. At the same time, "anti-bodies" have to be artfully cultivated by being part of strong scholarly practices such as having one's emerging understandings discussed and challenged by STS colleagues. Could recommending such artful contamination through engaging with the frictions within the field of vaccination be considered as intervention methods advice? What would intervention as method look like if Martin engaged more closely with the internal diversity and frictions among vaccination actors? And what would there be to learn about the internal dynamics and diversity among them? 


\section{Attend to Actors' Normative Intent}

Experimental interventions are bound to be weighed within what Becker called a "hierarchy of credibility," meaning that a contribution will be considered as more credible a priori if it confirms the existing hierarchical ordering within a controversy-and vice versa. In this sense, it is unsurprising that an attempt to "defend free speech," which treated the contributors to the debate equally within an unequal existing hierarchy, wasn't particularly welcomed-a finding that Martin rightly analyzes in the light of his important earlier publications on this topic, which would predict just that. Precisely because the call for free speech aims at treating all actors equally, this challenges the existing hierarchical ordering within the controversy and, as a consequence, will be perceived as a partial move merely benefitting the vaccination critics. But perhaps how a contribution is perceived does not solely depend upon how it fits in or challenges existing social hierarchies. Could another reason for the strong pushback to Martin's intervention also be related to the fact that arguing for free speech hardly attends to the normative intent actors bring to the issue of vaccination? In the case of the controversy over vaccination, both sides now criticize the other side for the fact that their approach harms vaccine-recipients. Defending free speech without taking into account how this relates to actors' normative intent-that of safeguarding recipientsresembles earlier critiques of medical sociology of which it was said that "the investigator stood with his or her back to the heart of medicine and studied the 'social phenomena' surrounding it" (Casper and Berg 1995, p.397), whereby some of the issues that mattered most to patients and health care professionals--clinical outcomes-were left out of the analysis.

The methodological advice that could follow from these observations is to consider how possible content-related arguments about vaccination would need to play out within a free speech argument to do something different than reifying the sides of the controversy and their hierarchies. What are the risks-perhaps even in clinical terms-of the exclusion of vaccination-critical voices that currently take place? And which vaccination actors would care about those risks just as much as the critics themselves? How would anti-vaccination activists need to rethink their concerns to make them be heard? And could an experiment in blurring the free speech argument with concerns about vaccination possibly lead to interesting lessons for thinking about free speech, especially in times where problematic understandings of "freedom" have become an important instrument for intolerance through political extremism? Intervention could then not be geared towards merely defending free speech, but rather toward learning about it-if that would be a research topic one is interested in.

So rather than thinking about the question of intervention as "a gap in STS research methodology," I hope that these resources from STS and sociology at large are helpful in thinking about intervention as method. I thereby hope to have pointed to an alternative to approaching intervention strategically, an alternative that maximizes its methodological potentials for STS scholars interested in engaging in controversies in order to learn more about them as well as about their own normative attachments. Although none of the guidance I explore would give Martin or any other scholar any form of detailed instructions on what to do, it could certainly help to think methodologically about intervening, making for scholarship we can care about in ways that do not contrast the academic and the personal.

A process analyzed particularly well in by Epstein (1996).

I thank Gary Lee Downey for pointing out this important consequence. 


\section{Non-Strategic Difference and STS Beyond the Linear Model}

One of the important arguments that Martin mobilizes in favor of a more strategic take on intervention is that he feels that STS is largely stuck in a linear model when it comes to its own knowledge practices. Martin argues that STS prioritizes developing greater understanding of phenomena, which can then be beneficial for both knowledge and society. Drawing on philosopher of science Nicolas Maxwell, he calls this a "philosophy of knowledge" that corresponds to the linear model of first developing better knowledge and then impacting society. In contrast, Martin calls for a shift to a "philosophy of wisdom" that starts with selecting "areas of social importance (for example poverty, peace, health, environment) without assuming that obtaining knowledge is the key goal." He illustrates the need for such a shift by indicating how the study of social movements seldom provides anything to activists that "they can directly apply." According to Martin, this points to "the neglect of strategy and tactics." There seem to be at least two ironies about his argument. First, little seems more linear to me than the idea that STS should develop tactics that activists could directly "apply." Second, I guess that the SAVN actors, that is the pro-vaccination forces, would have a word or two to say about Martin arguing that we should start from concerns like health, a concern they thought they needed to protect by all possible means from "quacks" and their accomplices like Martin.

As attractive as a philosophy of wisdom may sound, I doubt that it would be best served by sentimentally fixing the areas of social importance, especially since this produces an inverted linear model of stable normativity traveling into the world through strategic intervention. Perhaps our best shot at wisdom would be to do all we can to postpone knowing what "social importance" could possibly mean in a specific setting. One way to find out would then be to experiment with intervening in the practices concerned. The surprising normative outcomes that I came across when intervening in health care practices would surely be better served by wisdom appearing as an outcome, than by it getting it stabilized as a starting point.

Designing intervention experiments that avoid sentimentality challenges the linear model of knowledge production, not by inverting the linearity, but by extending non-linear scholarship to our own and others' normativities. This may sound like a scary move, especially for those who want to bring STS in line with what they see as its "activist roots," and since, as we learned from ethical philosophy, "the amoralist, or even his more theoretical associate the relativist, is presented ... as an alarming figure, a threat" (Williams 2011 [1985], p.25). Yet I would argue that it is precisely this extension of non-linearity to normativity that contributes to what seems to be a current revival in STS scholars' interest' in intervention: it finally allows STS scholars to take their concerns about the practices they are involved in

- I do not have the space here to go into these, but to name but a few they include: doctors being marginalized by their patients; nurses whom I expected to be doing skillful invisible work but who turned out to not know some of the basics about their daily activities; and health care market arrangements that were better able at entangling quality and competition when market devices where of poorer quality.

- Evidenced most recently by the large STS Making and Doing program at the 4 S meeting in Denver, with over 50 participants, and covering a wide range of topics and approaches. See for a first attempt at analyzing some of those projects (Downey and Zuiderent-Jerak 2016). 
seriously without violating their equal attachment to reflexivity, unpredictability, situatedness and mess.

In honesty, I have always felt deeply uncomfortable about linking STS to activism," not because there are no matters that I care about, but because the inverted linear model it endorses forces me to choose between an activist identity and a constructivist one. That is a choice that I have always felt the need to resist: some choices are simply best not made and I was drawn towards more symmetrical ways of relating personal and scholarly concerns. Now, thinking with Star through Martin's contribution, I have become all the more curious, if not optimistic, to continue learning how STS scholars, partly through considering intervention as method, may dwell in what Star called the "high tension zone or the complexity of the relationships involved in simultaneous multiple membership" (Star 1991, p.51). After all, that was the main thing that Star feared STS was losing through ANT analyses: the experience of multiple membership and multiple marginalities. If intervention as method allows scholars to explore what it means to live the multiple membership of societally and academically concerned communities, it may thereby be able to recover some of this experience that considering intervention strategically would make us lose.

\section{Acknowledgements}

This comment benefited much from conversations with Sonja Jerak-Zuiderent and Gary Downey. I thank Katie Vann and Daniel Kleinman for the invitation and encouragement to think with this article and for their helpful comments on an earlier version of this comment.

\section{References}

Becker, H. S. 1967. "Whose Side Are We On?" Social Problems 14 (3):239-247.

Casper, M. and M. Berg. 1995. "Constructivist Perspectives on Medical work: Medical Practices and Science and Technology Studies." Science, Technology, \& Human Values 20 (4):395-407.

Downey, G.L. and T. Zuiderent-Jerak. 2016. "Making and Doing: Engagement and Reflexive Learning in STS." In Handbook of Science and Technology Studies (4th edition), edited by U. Felt, R. Fouché, C. Miller and L. Smith-Doerr. Cambridge, MA: The MIT Press.

Epstein, S. 1996. Impure Science: AIDS, Activism, and the politics of knowledge. Berkely: University of California Press.

Galis, V. and F. Lee. 2014. "A Sociology of Treason: The Construction of Weakness." Science, Technology, \& Human Values 39 (1):154-179.

Goldenberg, M.J. 2006. "On Evidence and Evidence-based Medicine: Lessons from the Philosophy of Science." Social Science \& Medicine 62 (11):2621-2632.

Jensen, C.B. 2007. "Sorting Attachments: on Intervention and Usefulness in STS and Health Policy." Science as Culture 16 (3):237-251.

Jensen, C.B. 2008. "Sociology, Systems and (Patient) Safety: Knowledge Translations in Healthcare Policy." Sociology of Health \& Illness 30 (2):309-324.

\footnotetext{
". E.g. Woodhouse et al. (2002).
} 
Jerak-Zuiderent, S. 2015. "Keeping Open by Re-imagining Laughter and Fear." The Sociological Review 63 (4):897-921. doi: DOI: 10.1111/1467-954X.12221.

Kember, S. 2003. Cyberfeminism and Artificial Life. London, New York: Routledge.

Latimer, J. and Skeggs, B., (2011), "The politics of imagination: keeping open and critical", The Sociological Review, 59 (3): 393-410.

Martin, B. 2016. "STS and Researcher Intervention Strategies." Engaging Science, Technology, and Society 2: 55-66. DOI:10.17351/ ests2016.15.

Sackett, D.L., W.M.C. Rosenberg, J.A. Gray, R. B. Haynes, and W. Scott Richardson. 1996. "Evidence Based Medicine: What it is and What it isn't." British Medical Jounal 312 (7023):71-72.

Star, S.L. 1991. "Power, technology and the phenomenology of conventions: on being allergic to onions." In A sociology of Monsters:Eessays on Power, Technology and Domination, edited by John Law, 25-56. London: Routledge.

Webster, A. 2007. "Crossing Boundaries Social Science in the Policy Room." Science, Technology, \& Human Values 32 (4):458-478.

Whitehead, A.N. 2011 [1926]. Science and the Modern World. Cambridge: Cambridge University Press.

Williams, B. 2011 [1985]. Ethics and the Limits of Philosophy. Oxon, UK: Routledge.

Woodhouse, E., D. Hess, S. Breyman, and B. Martin. 2002. "Science Studies and Activism: possibilities and problems for reconstructivist agendas." Social Studies of Science 32 (2):297-319.

Zuiderent-Jerak, T. 2010. "Embodied Interventions-Interventions on Bodies: Experiments in Practices of Science and Technology Studies and Hemophilia Care." Science, Technology, \& Human Values 35 (5):677-710.

Zuiderent-Jerak, T. 2015. Situated Intervention: Sociological Experiments in Health Care. Cambridge: MIT Press.

Zuiderent-Jerak, T., F. Forland, and F. Macbeth. 2012. "Guidelines should reflect all knowledge, not just clinical trials." British Medical Journal 345 (e6702). 